\title{
Multiple predator species alter prey behavior, population growth, and a trophic cascade in a model estuarine food web
}

\section{PL Reynolds}

Virginia Institute of Marine Science

JF Bruno

Follow this and additional works at: https://scholarworks.wm.edu/vimsarticles

Part of the Ecology and Evolutionary Biology Commons, and the Marine Biology Commons

\section{Recommended Citation}

Reynolds, PL and Bruno, JF, Multiple predator species alter prey behavior, population growth, and a trophic cascade in a model estuarine food web (2013). Ecological Monographs, 83(1), 119-132.

$10.1890 / 11-2284.1$

This Article is brought to you for free and open access by the Virginia Institute of Marine Science at W\&M ScholarWorks. It has been accepted for inclusion in VIMS Articles by an authorized administrator of W\&M ScholarWorks. For more information, please contact scholarworks@wm.edu. 


\title{
Multiple predator species alter prey behavior, population growth, and a trophic cascade in a model estuarine food web
}

\author{
Pamela L. Reynolds ${ }^{1,2,3}$ and John F. Bruno ${ }^{1}$ \\ ${ }^{1}$ Department of Biology, University of North Carolina, Chapel Hill, North Carolina 27599-3280 USA \\ ${ }^{2}$ Department of Biological Sciences, Virginia Institute of Marine Science, College of William and Mary, Gloucester Point, \\ Virginia 23062-1346 USA
}

\begin{abstract}
Predators can influence prey population dynamics by affecting prey behaviors with strong fitness consequences, with cascading effects on lower trophic levels. Here, we demonstrate that multiple predator species can nonconsumptively influence prey population growth and the strength of a trophic cascade in a model marine community. We exposed the herbivorous amphipod Ampithoe longimana to olfactory and visual cues from three common predators (pinfish, mud crabs, brown shrimp) singly and together in a multiple-predator assemblage to quantify the nonconsumptive effects (NCEs) of predator identity and the presence of multiple predators on prey population and community-level metrics. The presence of predator cues, particularly those of the pinfish and the multiple-predator treatments, decreased prey population growth and influenced primary and secondary production. To explore mechanisms underlying the observed NCEs in the experimental communities and their potential influence in the field, we quantified individual prey behavioral responses (changes in grazing rate, diet preference, dispersal, colonization) in the presence of predator cues. Predator cues decreased prey grazing, dispersal, and colonization but did not affect prey diet preference. Given the persistence of NCEs over time and the fact that trophic cascades are common features of marine systems, changes in marine predator communities may have widespread effects on predator-prey behavioral interactions with consequences for ecosystem function even in areas of weak predation pressure.
\end{abstract}

Key words: amphipod; antipredator behavior; diversity; food web; marine; multiple predator; nonconsumptive effects; predator-prey interactions; trophic cascade.

\section{INTRODUCTION}

Predators can control prey populations by reducing their densities via consumption and/or a variety of nonconsumptive mechanisms (Abrams 1995). Nonconsumptive effects (NCEs) of predators include changes in prey foraging, vigilance, mating, and habitat selection (see reviews by Lima and Dill 1990, Berger 2010). While antipredator behavior may impose immediate fitness costs, such behaviors may be beneficial over time and result in a net fitness increase for prey exposed to strong predation pressure (Boeing et al. 2010). Costs of this behavioral plasticity, including decreased births and/or individual size or growth rates, can drive prey population cycles and may influence trophic interactions (Preisser et al. 2005, Peckarsky et al. 2008). NCEs can also affect ecosystem functioning by altering plant diversity, productivity, nutrient dynamics, trophic transfer efficiencies, and energy flux (see reviews by Schmitz 2008, Schmitz et al. 2010). NCEs can amplify the impact of rare or less-effective predators (Peacor 2002), and operate on larger spatial scales than direct predation

Manuscript received 22 December 2011; revised 19 June 2012; accepted 20 June 2012; final version received 30 July 2012. Corresponding Editor: W. E. Snyder.

${ }^{3}$ E-mail: Reynolds@vims.edu
(Orrock et al. 2008) with effects on community assembly and development (Resetarits and Binckley 2009, Kraus and Vonesh 2010). While NCEs appear to be common in marine systems (Raimondi et al. 2000, Dill et al. 2003, Heithaus et al. 2008), little is known about the long-term influence of these interactions on prey populations and their cascading effects on lower trophic levels in marine food webs. Nearly all work on prey behavior and NCEs in aquatic systems was conducted within one prey generation and measured only a few behavioral responses or fitness components (e.g., McIntosh and Peckarsky 1999, Trussell et al. 2003, Byrnes et al. 2006, Molis et al. 2011), although recent work primarily in terrestrial systems has greatly expanded our appreciation for the persistence of NCEs over space and time (e.g., Berger et al. 2008, van der Merwe and Brown 2008, Boeing et al. 2010, Trussell et al. 2011).

To understand the full ramifications of NCEs for natural systems, it is necessary to quantify not only antipredator behaviors and their short-term benefits for individual prey, but also the associated population-level consequences (e.g., Peckarsky and McIntosh 1998). For example, frequent predator avoidance might increase survival yet still decrease reproductive fitness by reducing grazing time, energy intake, growth, and fecundity. Therefore, predator NCEs could in theory 
A

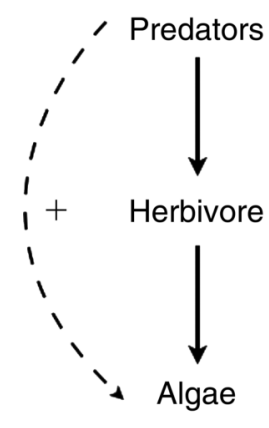

$\mathrm{B}$

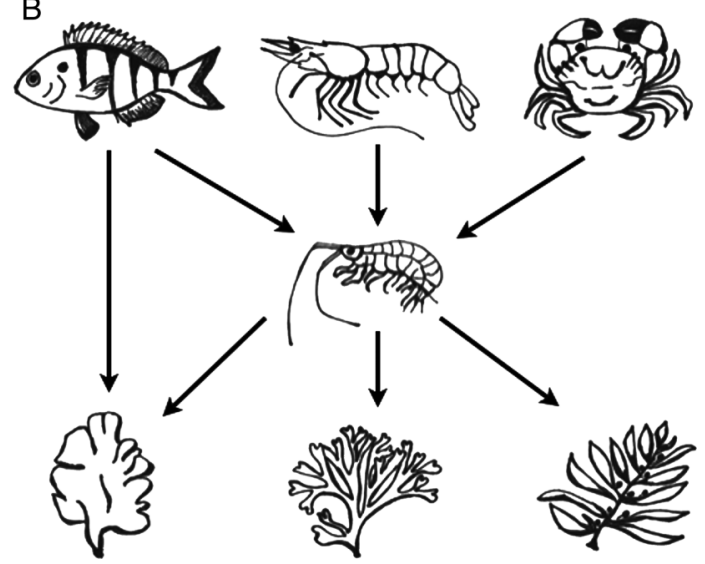

FIG. 1. Trophic cascade (A) with direct effects (solid arrows) and indirect effects (dashed arrows) arrows and (B) experimental food web. Algae and amphipod images are redrawn from Schneider et al. (1991) and Bousfield (1973).

regulate prey density over time even if direct consumption of prey by predators is low or precluded, such as in structurally complex habitats with abundant prey refugia (Nelson et al. 2004, Creel 2011). But, detecting NCEs on fitness parameters is challenging since prey may compensate for the costs of a specific antipredator behavior by adjusting other behaviors, such as increasing foraging or other activities during periods of reduced predation risk (Lima and Bednekoff 1999). Additionally, it is possible that starving prey or prey facing significantly reduced fitness from a given antipredator behavior may increase risk-taking behaviors in the presence of predators (e.g., Lönnstedt and McCormick 2011), although the benefit of this behavioral strategy is not generally supported in the literature (Bolnick and Preisser 2005).

As it can be difficult to isolate the role of NCEs when predation is allowed to occur, experiments partitioning behavioral effects are necessary to address the persistence and ramifications of prey antipredator responses. However, NCEs are rarely considered in a realistic food web context and nearly all NCE studies use a single predator species despite the well-demonstrated importance of predator richness and composition in regulating predator-prey interactions (Sih et al. 1998, Heithaus et al. 2008). The presence of additional predator species may affect specific prey behaviors (i.e., grazing rates or habitat use) as well as the efficiency of the predator community at capturing prey (Crowder et al. 1997, Byrnes et al. 2006, Martin et al. 2010, Steffan and Snyder 2010).

Here we investigate the NCEs of three predators (pinfish, brown shrimp, and mud crabs) on their herbivorous amphipod prey (Ampithoe longimana) and on primary producers in a model benthic, marine community. We exposed experimental communities in outdoor mesocosms to olfactory and visual cues from predator monocultures and polycultures and measured their effects on prey populations and primary and secondary production. We then conducted a series of laboratory and field experiments to examine specific prey antipredator behavioral responses that may contribute to the observed strength of NCEs in our experimental communities, and the potential importance of NCEs in the field.

\section{Material and Methods}

\section{Study system and experimental organisms}

The experimental communities were based on a shallow, subtidal food web in Bogue Sound, North Carolina, USA (Fig. 1). Experimental species chosen in this study are common and generally co-occur in shallow, sub-tidal habitats in North Carolina (Hay and Sutherland 1988). We selected the herbivorous amphipod Ampithoe longimana as our focal prey (e.g., grazer) due to its abundance and strong effects on algal biomass and composition (Duffy and Hay 2000). This tube-building amphipod is relatively sedentary and females produce multiple broods (Nelson 1978). $A$. longimana and other gammaridean amphipods are known to respond to cues from predatory fish (Wooster 1998, Reynolds and Sotka 2011). All experiments were stocked with adult female $A$. longimana (4-6 mm body size).

Predators included the highly mobile pinfish (Lagodon rhomboides) and two ambush predators: brown shrimp (Penaeus aztecus) and mud crabs (Panopeus herbstii). Pinfish actively forage in the water column and periphery of macroalgal beds, while brown shrimp and mud crabs hunt primarily within the complex macroalgal habitat or on the substrate. These predators were chosen due to their local abundance, similar size, varied foraging strategies, and known consumption of amphipods including A. longimana, as shown in Fig. 2 (see Appendix A for methods; Bruno and O'Connor 2005). Experimental predators ranged in wet mass from an average of $2.5 \mathrm{~g}$ to $4.2 \mathrm{~g}$ and from $1.8 \mathrm{~cm}$ to $5.8 \mathrm{~cm}$ in 
FIG. 2. Effects of different predator communities on the efficiency of prey capture. Lower recovery indicates greater predator efficiency. See Appendix A for methods. Values are means \pm SE. Different lowercase letters indicate significant $(P<0.05)$ differences from Tukey's HSD comparisons.

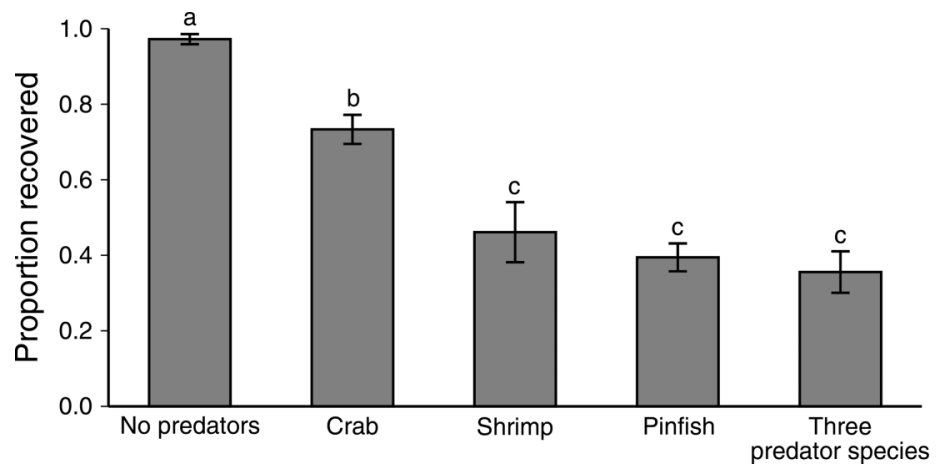

length (Appendix A). We collected predators within this size range to minimize variability in predator biomass among replicates across treatments. Predators in all experiments were fed crushed amphipods daily and were replaced as necessary.

Macroalgae used in experimental communities included Dictyota menstrualis, Sargassum filipendula, and Ulva lactuca, which are all consumed by $A$. longimana and tend to dominate hard substratum as well as marsh and seagrass habitats in North Carolina estuaries (Hay and Sutherland 1988, Bruno et al. 2005). Macroalgae and predators were used immediately after collection; grazers were maintained in cultures for one week prior to experimentation.

\section{Experimental design}

If predator-induced changes in prey behavior induce significant fitness costs, predator NCEs can influence prey population growth (Nelson et al. 2004) with consequences for the strength of a trophic cascade. To examine the NCEs of multiple predator species on prey and resource dynamics, we conducted a five-week community experiment in outdoor mesocosms. We also exposed individual prey to predator cues in the laboratory and field to examine specific antipredator responses (grazing, diet preference, dispersal, colonization) that may influence prey population dynamics and the strength of NCEs in experimental communities and in the field.

Predator treatments in all experiments included exposure of $A$. longimana to olfactory and visual cues from no, one, or all three predator species. Although olfactory cues are likely more informative of predation risk in turbid estuarine habitats, both olfactory and visual predator cues were featured in all experiments as prey responses to different predator species are known to vary with cue type (Martin et al. 2010). Because predator density can affect amphipod behavior (Wooster 1998), predator density was held constant in all experiments in a substitutive design of three predators per experimental unit across all treatments, which is within the range of typical field densities for these predators (O’Connor and Bruno 2009).
Predators were caged in all experiments and could not directly access or consume their prey (except the assessment of predator efficiency of prey capture; Fig. 2). While this approach precludes some potential cues that could convey predation risk for specific predator types (e.g., tactile vibrations of hunting predators as in Markl and Tautz [1975]), we suspect that such cues may be less useful pre-encounter indicators of predator presence and the degree of predation risk for our amphipod prey given their turbulent marine environment. Manipulating predator mouthparts and/or claws as employed in other studies to allow predators to forage freely without consuming their prey (e.g., Peckarsky and McIntosh 1998, Schmitz 1998) would only have been ethically possible for the brown shrimp and mud crabs and would therefore have confounded predator species identity with their ability to interact with their prey. This method may also have reduced prey pheromones (death cues) and predator kairomones, both known to be important cues for prey risk assessment (Venzon et al. 2000, Smee and Weissburg 2006, Turner 2008), and involved disruptions associated with frequent replacement of manipulated predators as they began to starve throughout the duration of the experiments, and was thus not employed here.

\section{Community experiment}

To quantify population- and community-level effects of NCEs, we performed a five-week experiment in $30-\mathrm{L}$ outdoor mesocosms with flow-through filtered seawater (see Bruno and O'Connor 2005). In these experimental communities, we tested the effect of multiple-predator NCEs on prey populations and their resources. We manipulated $A$. longimana presence and predator cues for a total of 10 treatments ( $n=8$ replicates per treatment). Treatments with predators but no $A$. longimana were included to test whether predator excretions directly affect algal growth. Mesocosms were first stocked with an ambient macroalgal community. We attached one $15-\mathrm{g}$ thallus of each macroalgae species ( $45 \mathrm{~g}$ total) to a $25 \times 25$ $\mathrm{cm}$ Vexar mesh screen (Memphis Net \& Twine, Memphis, Tennessee, USA) secured to the bottom of 12-L tanks such that the algae floated upright in a natural orientation (see images in Appendix B). This macroalgal wet mass was 


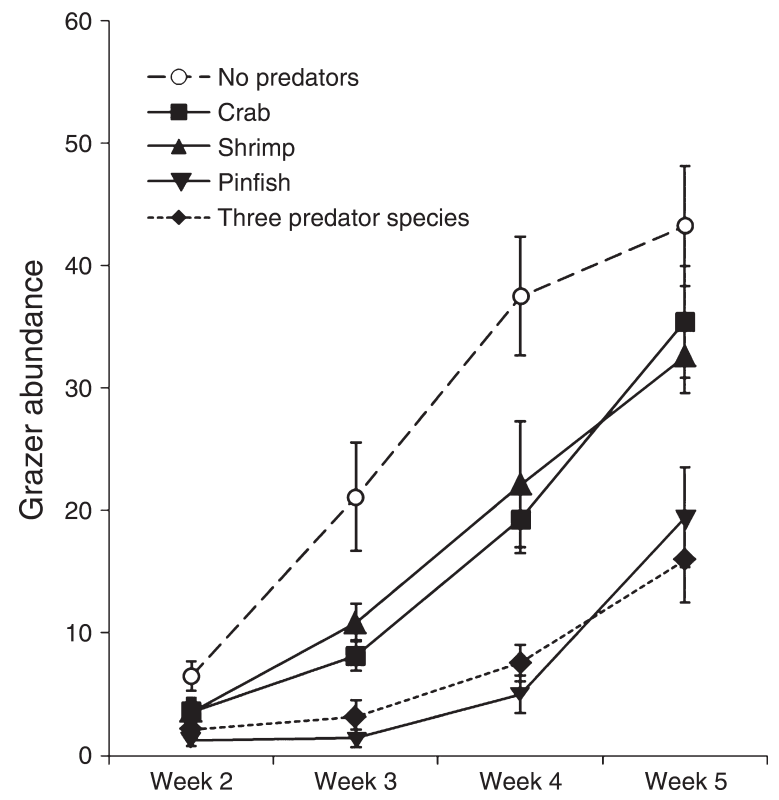

FIG. 3. Effects of predator cues on the number of grazers recovered on dispersal patches over time during the community experiment. Values are means $\pm \mathrm{SE}$.

comparable to field densities (Bruno et al. 2005). The next day, mesocosms received 0 or 30 fecund female $A$. longimana. Fecund females were added to ensure constant initial population demographics across replicates. The following day, mesocosms received visual and olfactory cues from predators caged in a clear 3-L tank weighted with a rock and fixed with 50- $\mu \mathrm{m}$ screens to allow passage of visual and chemical cues while preventing direct predation. Although individual predator biomass varied across replicates (one-way ANOVA, $F_{3,28}=11.41, P<0.0001$ ), total predator biomass per replicate did not differ between the average single-predator species and the three-predator species treatments ( $P=0.49$, LSM planned contrast).

Mesocosms received gravel-filtered seawater from a dump-bucket system (see description in Bruno and O'Connor 2005) to maintain aeration and simulate turbulence of local subtidal habitats. Temperature, nutrients, salinity, and light levels in mesocosms were comparable to field conditions at Radio Island and in the nearby Bogue Sound, North Carolina (Bruno et al. 2005, O'Connor and Bruno 2009). Before entering mesocosms, seawater passed through $200-\mu \mathrm{m}$ mesh filter bags to minimize immigration and fouling. Screens on the outflow of each mesocosm prevented emigration. Mesocosms were randomly assigned to tables and were rearranged every two days to reduce positioning artifacts. The experiment began on 6 July 2008 and ran for 35 days, or conservatively for two overlapping generations of $A$. longimana (Cruz-Rivera and Hay 2001). Replicates were excluded if the predators escaped or the mesocosm cracked (six mesocosms total).
Throughout the experiment we nondestructively measured a proxy for prey density by quantifying the number of $A$. longimana on dispersal patches within the mesocosms. Once a week, we tied an 8 -g thallus $(\sim 25 \mathrm{~cm}$ long) of S. filipendula to a small patch of Vexar and attached it to the bottom center of each mesocosm. Because A. longimana are often more active at night (E. Sotka, personal communication), patches were deployed in the evening and collected the following morning $(\sim 12$ hours). Individuals on patches were live counted and returned to their respective mesocosms within two hours of removal.

To assess predator NCEs on prey populations, we quantified final prey abundance and population size structure by counting all individuals and size classing them using a series of nested sieves after preservation in $70 \%$ ethanol. Ash free dry mass and secondary production was then estimated per mesocosm from body-size distributions following Edgar (1990). Assuming generation time $(T)$ was equivalent between predator-cue treatments (mean age of females at offspring birth $=14$ days; Sotka and Reynolds 2011), we calculated the fundamental net reproductive rate $(R$ or $\lambda$ ) using the equation $R=N_{1}\left(N_{0}\right)^{-1}$, where $N$ is the initial population density at a given time (here, 0 or 1 ), and the intrinsic rate of natural increase $(r)$ using the equation $r=\ln R(T)^{-1}$ (Begon et al. 2006). This calculation was used as we found no evidence for density dependence (see Fig. 3), and overlapping generations are implicit in the equation. We measured final macroalgal biomass per species, and quantified chlorophyll $a$ concentration from one $2 \times 2 \mathrm{~cm}$ tile in each mesocosm as a proxy for microalgal accumulation (for methods, see Appendix C).

\section{Behavioral experiments}

To explore potential mechanisms for the predator NCEs on prey population and community-level dynamics observed in the experiment, we quantified predator cue-induced changes in A. longimana grazing rates and diet preference in the laboratory in July 2008. To further assess potential predator NCEs on natural populations with open prey dispersal, we examined the effects of predator cues on prey dispersal in the laboratory and colonization of new algal substrate in the field in July 2008 and May 2009, respectively. Temperature, light, and salinity in laboratory assays were within the range of ambient conditions experienced throughout the tidal cycle in the field $\left(24^{\circ} \mathrm{C}, \sim 400 \mu \mathrm{mol} \cdot \mathrm{m}^{-2} \cdot \mathrm{s}^{-1} \cdot \mu \mathrm{A}, 32 \mathrm{ppt}\right.$, respectively [O'Connor 2009]). As in the community experiment, predator treatments included the exposure of $A$. longimana to olfactory and visual cues from all five predator treatments.

Grazing.-One female A. longimana was placed in a clear plastic 9-mL cup with $50 \mathrm{mg}$ of freshly collected $S$. filipendula. Cups were weighted with small pebbles to provide additional habitat. Four cups with $A$. longimana were paired with four no-grazer control cups and placed 
within an 11.4-L tank stocked with the appropriate predator treatment $(n=8$ replicates per treatment for a total of 320 cups). Tanks were provided with an air stone and flow-through filtered seawater. Small holes in the clear plastic cups allowed transmission of both visual and olfactory cues from the predators, which could swim freely around the cups but could not directly access their prey. To determine grazing rates of $A$. longimana across predator treatments, we first compensated for autogenic changes in the algae in control cups after 3 days according to Sotka and Hay (Sotka and Hay 2002) using the equation $G_{\mathrm{i}}\left(C_{\mathrm{f}} / C_{\mathrm{i}}\right)-G_{\mathrm{f}}$ for grazer presence $G$ and absence $C$, and initial i and final $\mathrm{f}$ macroalgal wet mass. Cups were excluded if the grazer died or molted (11 cups total).

Diet preference.-To assess the potential effect of predator cues on the preference of $A$. longimana for a chemically defended alga ( $D$. menstrualis) in the community experiment, amphipods were exposed to cues from predators in a similar setup to the grazing assay ( $n=12$ replicates). Here, however, each tank housed one cup with and one without $A$. longimana, and cups received feeding screens with reconstituted rather than fresh algal tissue. Screens were prepared using either freeze-dried, ground D. menstrualis or the highly palatable Ulva linza mixed with agar and spread over pieces of window screen 5 squares $\times 6$ squares in size (for detailed methods and recipe, see Reynolds and Sotka [2011]). Each cup received one screen of each algal species. Cups were checked daily and each replicate assay was ended when $>30 \%$ of one screen or $40 \%$ total was consumed. Cups were excluded from the analysis if the amphipod died before making a choice (10 amphipods) or molted (6 amphipods).

Dispersal.-To further assess potential effects of predator NCEs on prey in natural systems open to dispersal, we attached one 15-g thallus of each macroalgae species ( $45 \mathrm{~g}$ total) to a $25 \times 25 \mathrm{~cm}$ Vexar mesh screen secured to the bottom of $12-\mathrm{L}$ tanks such that the algae floated upright in a natural orientation. This macroalgal wet mass was comparable to field densities (Bruno et al. 2005). All tanks received 30 female $A$. longimana. Predators were caged within the tanks as in the community experiment ( 5 levels, $n=6$ replicates). Tanks were provided with flow-through seawater; two 2 $\mathrm{cm}$ diameter holes allowed water to slowly flow from this tank downward into a "dispersal" tank and provided a unidirectional avenue for grazer dispersal (see image in Appendix B). To assess predator cue treatment effects on grazer dispersal, we compared the proportion of recovered grazers in the dispersal tank across treatments after one week.

Field colonization.-We then examined the effects of predator cues on prey colonization of new algal substrate. We stocked cylindrical Vexar cages $(20 \mathrm{~cm}$ tall $\times 12 \mathrm{~cm}$ diameter; mesh opening of $0.3 \mathrm{~cm}$ ) with no predators, or with one or three predator species, at constant density $(n=10)$. Two thalli $(10 \mathrm{~g}, \sim 30 \mathrm{~cm}$ long each) of $S$. filipendula were attached to the outside of each cage such that the algae floated upward in a natural orientation and that predators inside the cage could not access them (see Appendix B). Cages were submerged $0.5 \mathrm{~m}$ from the surface at low tide and placed $>1 \mathrm{~m}$ apart to rebar fixed in sand adjacent to the jetty at Radio Island, North Carolina. After 72 hours, all S. filipendula was removed and the number of grazers on the algae live counted. Replicates were discarded if the algae or cage disappeared or the predators escaped (three cages total). Observations at low tide did not indicate any bias of natural predator movements between cages, and thus observed differences in grazer abundances across predator treatments were unlikely due to differential attraction to the cages and predation by ambient predator communities.

\section{Analysis}

To assess the effects of predator treatment on prey abundance over time in the community experiment, we used a linear model with two fixed effects (predator treatment, five levels; time point, four levels) and correlated errors fitted with a PROC MIXED procedure with a Kenward-Rogers correction in SAS version 9.2 (SAS Institute 2008) to generate the estimated $F$ statistics. The best-fit model had a correlation structure of AR1. As the next prey generation was likely produced between the first and the second sampled time point, and there was a significant interaction between time and treatment when the first time point was included (e.g., there was no significant interaction of predator treatment with time after two weeks, $F_{8,63.9}=1.68, P=$ 0.1218 ), we removed this level and reanalyzed the data for only the last three time points. Linear models with one fixed effect (predator treatment, five levels) and two fixed effects (grazer and predator treatment) were fitted with PROC MIXED to test treatment effects on final prey abundance (natural $\log$ ) and the algal community (natural log macroalgal biomass, chlorophyll $a$ concentration), respectively. We used a two-factor MANOVA in PROC GLM to test the effects of predator and grazer treatments on final macroalgal community structure (see Appendix D). Predator treatment effects on grazer abundances across size classes were assessed with a quasi-Poisson log-linear model by calculating odds ratios comparing adjacent size categories using $\mathrm{R}$ (version 2.14.0; $\mathrm{R}$ Design Core Team 2011; see Appendix E).

To assess the effects of predator treatment on prey grazing and diet preference, we used a linear model with tank (40 and 44 levels, respectively) as a random effect nested within predator treatment (five levels) using PROC MIXED in SAS. The natural log of the calibrated total amount of algae consumed per individual $A$. longimana per day was used in the grazing rate analysis. As there was no loss of algae when grazers were absent in the diet preference experiment, we compared the proportion of $D$. menstrualis consumed per amphi- 

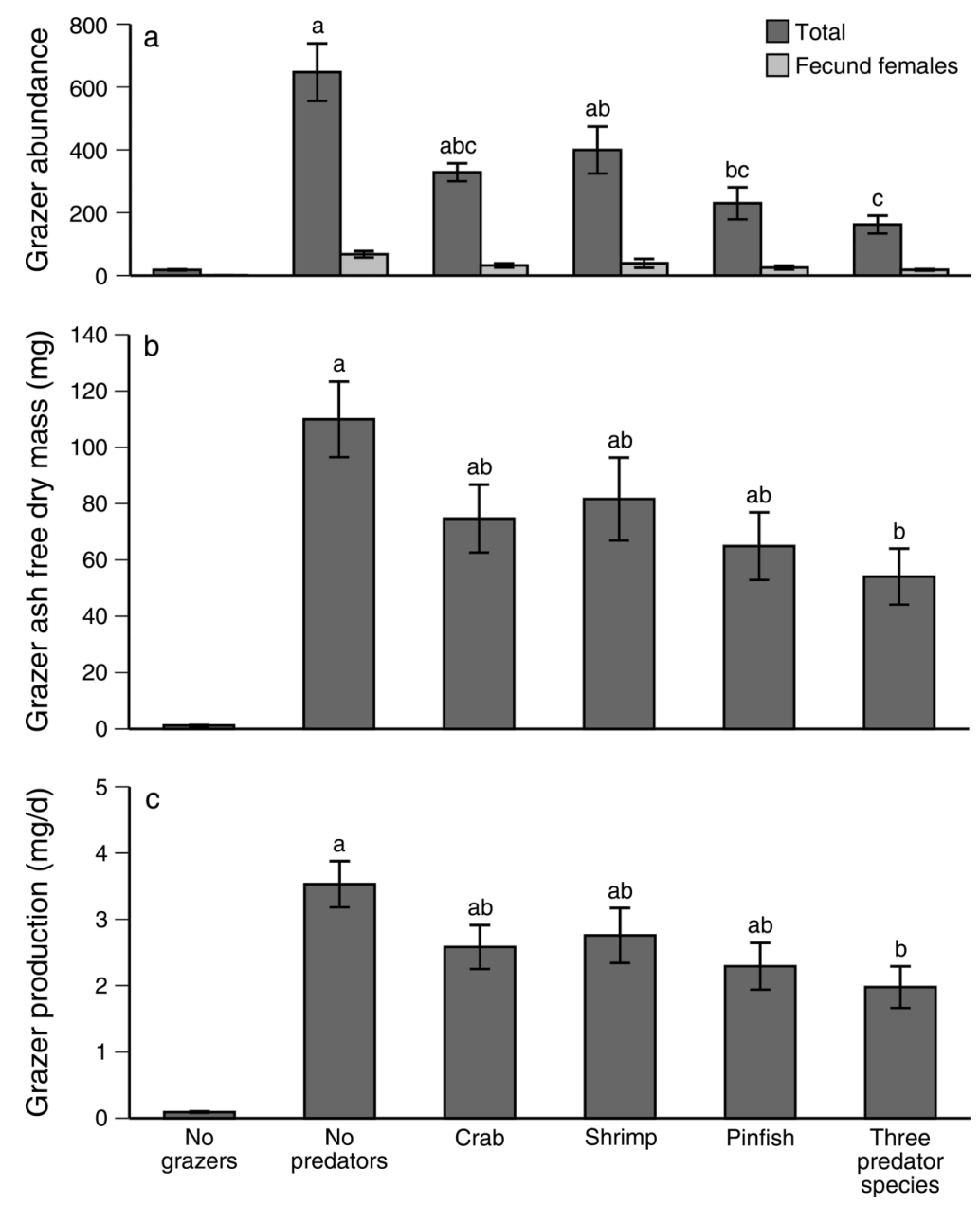

FIG. 4. Effects of predator cues on grazer (a) abundance and estimated (b) biomass and (c) production in the community experiment. Incidental amphipod immigration (no grazers treatment) was minimal. Values are means \pm SE. Different lowercase letters indicate significant differences $(P<0.05)$ from comparisons based on Bonferroni corrections.

pod across predator treatments. PROC MIXED was also used to test the effect of predator treatment on prey dispersal (proportion dispersed to total individuals recovered) in the laboratory and colonization (squareroot abundance) in the field. Data were transformed to meet assumptions of normality and homoscedacity (Underwood 1997).

We calculated diversity metrics $D_{\mathrm{T}}$ and $D_{\mathrm{MAX}}$, as in Loreau (1998), to test for nonadditive "richness effects" in the predator polyculture treatments. Positive $D_{\mathrm{T}}$ values indicate overyielding (performance of the threepredator species treatment is higher than the average single-species treatment) and positive $D_{\operatorname{MAX}}$ values indicate that the overyielding is trangressive (performance of the three-predator species treatment is higher than the best single-species treatment). If predator presence had a negative effect on the quantified response (grazing rate, dispersal, abundance, and so on), values were subtracted from the no predator controls prior to calculating $D_{\mathrm{T}}$ and $D_{\mathrm{MAX}}$.

\section{RESULTS}

\section{Community experiment}

All grazer populations grew throughout this experiment (Fig. 3) and incidental gazer immigration was minimal (Fig. 4a, "no grazers" treatment). Predator treatment and time influenced grazer abundance on dispersal patches deployed weekly throughout the experiment $\left(F_{4,34.7}=18.13, P<0.0001 ; F_{2,62.5}=51.50\right.$, $P<0.0001$, respectively). The effect of predator treatment was obvious after one grazer generation (week 3). Grazer abundance on dispersal patches was lower in the presence of predator cues (least squares means planned contrast of presence/absence of predator cues, $P<0.0001)$ and when cues were from all three predator species compared to the average single predator (least squares means planned contrast, $P=0.0103$ ). Although a likely approximation of total grazer abundance and an indicator of grazer population growth over time, these data must be interpreted with caution as predator cues 
TABLE 1. (A) Predator treatment (P) effects on the final abundance, estimates of ash free dry mass (AFDM), production of Ampithoe longimana, and predator and grazer $(\mathrm{G})$ effects on macroalgal wet mass and microalgal chlorophyll $a(\mathrm{chl} a)$ in the community experiment. (B) Predator (P) and grazer $(\mathrm{G})$ treatment effects on macroalgal composition (MANOVA) in the community experiment.

\begin{tabular}{|c|c|c|c|c|c|}
\hline \multicolumn{6}{|l|}{ A) ANOVAs } \\
\hline Final grazer abundance & $\begin{array}{l}\text { P } \\
\text { error }\end{array}$ & $\begin{array}{l}9.01 \\
8.78\end{array}$ & $\begin{array}{r}4 \\
31\end{array}$ & 7.95 & 0.0002 \\
\hline Grazer AFDM & $\begin{array}{l}\mathrm{P} \\
\text { error }\end{array}$ & $\begin{array}{l}13517.45 \\
35531.63\end{array}$ & $\begin{array}{r}4 \\
31\end{array}$ & 2.95 & 0.0356 \\
\hline Grazer production & $\begin{array}{l}\text { P } \\
\text { error }\end{array}$ & $\begin{array}{l}10.37 \\
28.01\end{array}$ & $\begin{array}{r}4 \\
31\end{array}$ & 2.87 & 0.0394 \\
\hline Macroalgal biomass & $\begin{array}{l}\mathrm{G} \\
\mathrm{P} \\
\mathrm{G} \times \mathrm{P} \\
\text { error }\end{array}$ & $\begin{array}{l}1.09 \\
1.20 \\
1.42 \\
5.33\end{array}$ & $\begin{array}{r}1 \\
4 \\
4 \\
65\end{array}$ & $\begin{array}{r}13.25 \\
3.65 \\
4.34\end{array}$ & $\begin{array}{l}0.0005 \\
0.0096 \\
0.0036\end{array}$ \\
\hline Macroalgal chl $a$ & $\begin{array}{l}\mathrm{G} \\
\mathrm{P} \\
\mathrm{G} \times \mathrm{P} \\
\text { error }\end{array}$ & $\begin{array}{r}275808.54 \\
54265.77 \\
41 \quad 153.12 \\
224479.49\end{array}$ & $\begin{array}{r}1 \\
4 \\
4 \\
65\end{array}$ & $\begin{array}{r}79.86 \\
3.93 \\
2.98\end{array}$ & $\begin{array}{r}<0.0001 \\
0.0064 \\
0.0254\end{array}$ \\
\hline \multicolumn{6}{|l|}{ B) MANOVA } \\
\hline Response variable & Factor & Wilks' lambda & $\mathrm{df}$ & $F$ & $P$ \\
\hline Community structure & $\begin{array}{l}\mathrm{G} \\
\mathrm{P} \\
\mathrm{G} \times \mathrm{P}\end{array}$ & $\begin{array}{l}0.65 \\
0.79 \\
0.75\end{array}$ & $\begin{array}{r}3 \\
12 \\
12\end{array}$ & $\begin{array}{r}11.18 \\
1.27 \\
1.62\end{array}$ & $\begin{array}{r}<0.0001 \\
0.2408 \\
0.0891\end{array}$ \\
\hline
\end{tabular}

may have reduced grazer mobility and patch colonization (see Results: Dispersal and field colonization experiments).

After 42 days, grazer abundance increased roughly 10 -fold (intrinsic rate of increase, $r=0.996$ ). Predator treatment affected final grazer abundance, estimated ash free dry mass, and production (Table 1A). Although effects varied among predator species (Fig. 4), on average, these responses were lower in the presence of predator cues $(P=0.0001, P=0.0049$, and $P=0.0059$ respectively, least squares means planned contrasts). On average, the lowest grazer abundances were observed in mesocosms exposed to cues from pinfish (pinfish monocultures and the three-predator species treatments, Fig. 4a).

Predator treatment did not affect the proportion of fecund female grazers $\left(F_{4,31}=0.37, P=0.8272\right.$; Fig. 4a) nor the average grazer brood size $\left(F_{4,31}=0.48, P=\right.$ $0.7508, n=4$ fecund females per replicate). Compared to the no-predator controls, the frequency of smaller grazer size classes decreased in the presence of predators (Fig. 5; Appendix E). Incidental grazer immigration was minimal (Fig. 4, "no grazers" treatment), and thus differences in final grazer densities are likely due to differences in population growth rates across predator treatments.

Grazer and predator treatments interactively affected final macroalgal biomass and chlorophyll $a$ concentration, a proxy for microalgal accumulation (Table 1A, Fig. 6). On average, the presence of grazers reduced final macroalgal biomass and microalgal chlorophyll $a$ (Fig.
$6 a, b)$. In the presence of grazers, only treatments with pinfish cues enhanced algae compared to the nopredator treatment (Fig. 6). Grazer, but not predator treatment influenced macroalgal structure (Table 1B, Fig. 6c, Appendix D).

\section{Behavioral experiments}

The presence and identity of predators affected most grazer behaviors (Fig. 6a-d). On average, predator cues reduced $A$. longimana feeding $\left(F_{4,35}=28.30, P<0.0001\right)$ and dispersal $\left(F_{4,25}=8.87, P=0.0001\right)$ in laboratory assays, as well as colonization in the field $\left(F_{4,42}=11.08\right.$, $P=<0.0001)$, but had no effect on $A$. longimana feeding preference for the chemically defended $D$. menstrualis $\left(F_{4,39}=1.11, P=0.3641\right)$.

\section{Discussion}

Our results indicate that nonconsumptive effects of multiple predators can have strong negative effects on prey density, possibly by reducing prey foraging and heightening other antipredator behaviors, with consequences for both primary and secondary production in a model estuarine community. Predator NCEs reduced individual prey grazing rates, prey population growth, and secondary production. We also found that in this system predator NCEs can reduce prey mobility in the field. While the observed NCEs were influenced by predator identity, the relative strength of these NCEs did not entirely mirror predator species-specific differences in their efficiency of prey capture. Additionally, we 

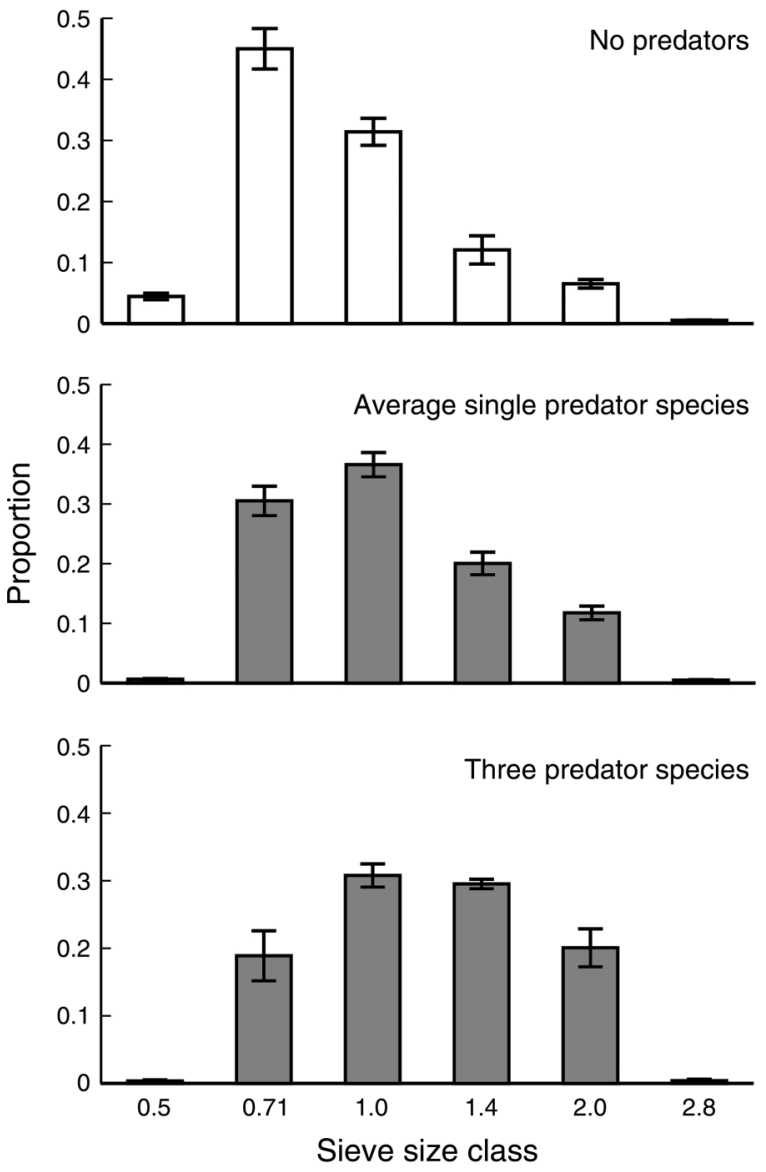

FIG. 5. Effects of predator cues on grazer size frequency distributions after five weeks in the community experiment. Size classes correspond to the mesh size $(\mathrm{mm})$ of the sieve on which the specimens were retained. Values are means \pm SE.

found that increasing predator species richness strengthened NCEs on prey population dynamics (Table 2) with broader consequences for other trophic levels.

Persistent predator cues led to lower prey densities after approximately two overlapping generations (Table 1A). Predator cues reduced grazer abundance by $49 \%$ on average compared to controls (Fig. 4a). This effect of predator cues on prey density could be explained by several mechanisms including decreased reproduction and/or survivorship from changes in prey reproductive physiology and body condition due to reduced feeding and/or elevated stress (see review by Creel and Christianson 2008, Peckarsky et al. 2008). In behavioral assays, adult female $A$. longimana consumed on average $26 \%$ less algal biomass in the presence of predator cues than in their absence (Fig. 7a), which could potentially reduce individual body condition and growth over time. Such reductions in feeding may decrease exposure to predators and lower overall predation risk (e.g., Giguère and Northcote 1987) but, over time, could lead to increased starvation risk for mothers (e.g., Stibor and Navarra 2000), lower offspring births via delayed reproduction and/or reduced brood sizes, and reduced juvenile survivorship with negative effects on population growth (Peckarsky and McIntosh 1998, Nelson et al. 2004, Pangle et al. 2007, Reynolds and Sotka 2011). Although physiologically stressed animals may reduce brood size with negative effects on birth rates (Lima 2009, Travers et al. 2010), the average proportion of fecund female grazers in experimental populations and their average brood size was not affected by the presence of persistent predator cues. This suggests that the observed NCEs of our predators on their prey populations were mediated by a change in female reproductive timing and/or juvenile survivorship.

Reduced survivorship or fecundity, as well as delayed reproduction upon exposure to predator cues have been observed for some Daphnia clones (Burks et al. 2000, Hanazato et al. 2001). Additionally, we have observed that A. longimana reared in water cultured with pinfish molt less frequently and reproduce several days later compared to individuals in control seawater (P. Reynolds, personal observation), supporting the thesis that predator cues may increase the amphipod's generation time and thus reduce the population growth rate. However, cues from predators are also known to promote the fitness of their invertebrate prey; early maturation as well as production of larger clutches leading to increased fitness have been observed in other Daphnia clones when exposed to predator cues (e.g., Castro et al. 2007, Boeing et al. 2010). In this case, earlier reproduction and larger clutches produced smaller mature females and neonates, a potentially adaptive response to size-selective predation by their fish predators (Castro et al. 2007). This may contrast with our study system, where average predator (pinfish) size changes rapidly throughout the season in the field and is known to affect biases in amphipod size class consumption (Nelson 1979b), and thus there may be little to no advantage for amphipods reproducing at smaller or larger body sizes.

Reduced maternal condition coupled with increased juvenile morality in the presence of predator cues may also affect prey size distributions. The frequency of small, juvenile prey individuals was lower in the presence of predator cues, especially pinfish (Fig. 5). However, increases in individual prey growth rates due to reduced resource competition in the presence of predators could have exacerbated our observed differences. For example, Peacor (2002) found that tadpoles grew more quickly in the presence of caged predatory larval dragonflies due to an increase in resource availability caused by an overall decrease in tadpole foraging. Similarly, predators could affect prey morphology by reducing prey activity. Johansson and Andersson (2009) found that carp gained more biomass in the presence of predators due to a decrease in swimming activity and an increase in energetic investment in growth. Regardless of the mechanism by which predator cues influenced prey population demographics, observed reductions in $A$. longimana population growth had strong consequences for their algal resources. 

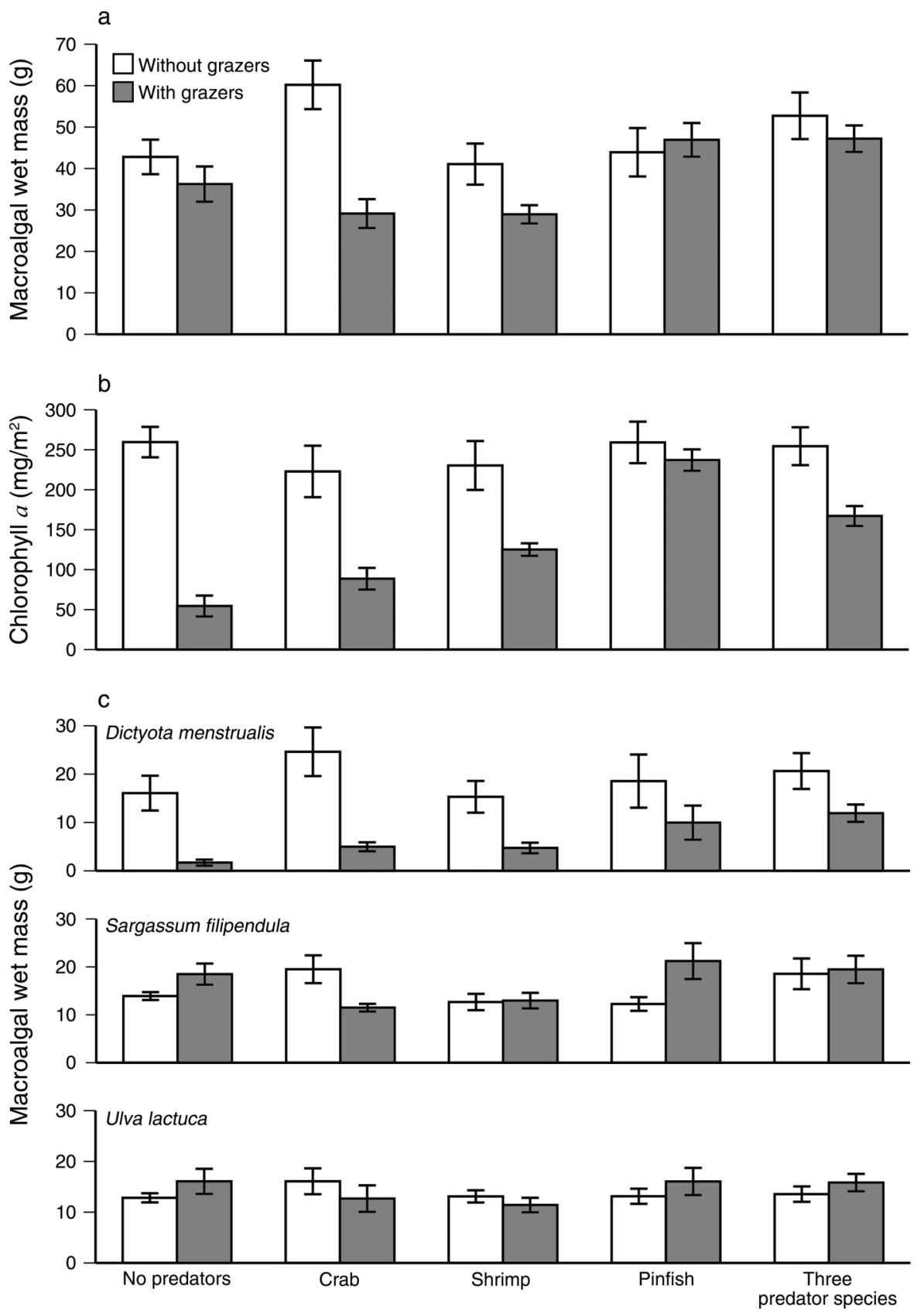

FIG. 6. Effects of grazer and predator cue treatments on (a) macroalgal biomass, (b) microalgal chlorophyll $a$, and (c) macroalgal community composition after five weeks in the community experiment. Values are means \pm SE.

We found that NCEs can affect final algal biomass and composition potentially by affecting prey population growth and grazing behavior (Figs. 4 and 6a; Appendix D). In the presence of grazers, cues from pinfish and the three-predator treatments promoted a sixfold increase in biomass of the chemically defended Dictyota menstrualis (Fig. 6c), a preferred food of $A$. longimana that is thought to provide a refuge from predation (Duffy and Hay 1991). Biomass of Sargassum filipendula and Ulva lactuca was largely unaffected by predator cues when grazers were present, supporting the hypothesis that observed changes in macroalgal composition were driven by changes in A. longimana grazing pressure on $D$. menstrualis. Unlike recent work in terrestrial systems in which cues from predatory spiders were found to alter grasshopper diet (Hawlena and Schmitz 2010), the presence of predator cues did not affect $A$. longimana preference for $D$. menstrualis 
TABLE 2. Diversity metrics ( $D_{\mathrm{T}}$ and $\left.D_{\mathrm{MAX}}\right)$ across experiments and response variables.

\begin{tabular}{lcr}
\hline \hline \multicolumn{1}{c}{ Response } & $D_{\mathrm{T}}$ & \multicolumn{1}{c}{$D_{\mathrm{MAX}}$} \\
\hline Community experiment & & \\
Macroalgae & 0.349 & 0.006 \\
Microalgae & 0.263 & -0.088 \\
Grazer abundance & 0.652 & 0.163 \\
Grazer estimated biomass & 0.541 & 0.239 \\
Grazer estimated production & 0.574 & 0.255 \\
Behavioral experiments & & \\
Grazing rate & 0.441 & -0.075 \\
Diet preference & 0.373 & 0.017 \\
Dispersal & 0.552 & 0.000 \\
Field colonization & 0.541 & -0.046 \\
\hline
\end{tabular}

Notes: Positive $D_{\mathrm{T}}$ values indicate a richness effect (the multiple species treatment performs better than the average single species treatment). Positive $D_{\text {MAX }}$ values indicate transgressive overyielding (multiple species treatment performs better than the best single-species treatment).

compared to a highly palatable alternative diet, $U$. linza (Fig. 7b; Sotka and Reynolds 2011). The observed interaction between predator and grazer treatments on primary production is not surprising given that, in the absence of grazers, predator cues had little overall effect on macro- and microalgae, while, in the presence of grazers, cues from treatments with pinfish (pinfish and three-predator species treatments) had generally positive effects on these producers (Fig. 6a, b). While predator excretions may enhance algal growth in some systems by increasing water column nutrient concentrations (e.g., Persson 1997, Layman et al. 2011), it is possible that ambient nutrient levels in Bogue Sound are sufficiently high to preclude nutrient limitation for algae in our experimental communities, and/or that the added inputs from most of our experimental predators were marginal.

\section{Role of nonconsumptive effects in open systems}

While our experimental mesocosms precluded amphipod immigration and emigration, predator NCEs may have wide-ranging effects on prey dynamics by altering prey movement in natural, open systems (Orrock et al. 2008). On average, we found that $38 \%$ fewer grazers dispersed from experimental tanks and $67 \%$ fewer grazers colonized field patches when predator cues were present (Fig. 7c, d). Cues from pinfish had the strongest effects on grazer mobility, reducing dispersal in the lab by $52 \%$ and colonization in the field by $74 \%$ compared to no-predator controls. These decreases may have unexpected consequences for natural populations, potentially stabilizing source populations while inhibiting sink populations. However, understanding the effects of predator induced changes in prey mobility on local population dynamics may be complicated by predation intensity. If prey mobility is reduced, prey density may increase over the short term in patches with predators due to reduced dispersal, but is predicted to ultimately decline due to active predator consumption and, possibly, reduced immigration (Sih 1994, Orrock et al. 2010).

\section{Effect of predator efficiency of prey capture}

The strength of NCEs may correlate with predator efficiency of prey capture, abundance and evolutionary history with their prey (Sih et al. 1998, Werner and Peacor 2003). The costliness of antipredator behavior suggests that prey should modify these behaviors in response to changes in predation risk; more efficient predators, or those with elevated prey consumption, should more strongly intimidate their prey (McIntosh and Peckarsky 1999). Although both shrimp and pinfish are equally efficient at capturing $A$. longimana in experimental mesocosms (Fig. 2; Nelson 1979a, $b$, Bruno and O'Connor 2005), pinfish consistently elicited stronger NCEs. Mud crabs, the predator species that consumed the least prey individuals in predation trials, elicited the weakest NCEs.

Recent work suggests that ambush predators such as shrimp or crabs should elicit stronger prey antipredator behavior (Preisser et al. 2007). However, we found the greatest NCEs in the presence of cues from an active predator (pinfish). Heightened NCEs of pinfish on $A$. longimana may be due to increased exposure to this predator in the field with seasonal variation in abundance or encounter rates. Additionally, caging of predators in the community and field experiments restricted their mobility and may have altered our estimates of predator efficiency of prey capture as well as prey perception of predation risk by providing prey with persistent, point-source cues of predator presence. However, this does not fully explain all results as the pattern of strongest NCEs by pinfish was also observed in grazing assays in which predator mobility was less constrained.

It is also possible that laboratory feeding studies (Fig. 2, Appendix A) overestimated predator efficiencies, which are likely to be lower and may be more similar in densely vegetated field habitats (Stoner 1982, Orth et al. 1984). Additionally, prey may exhibit adaptive risk assessment, where prey reduce antipredator behavior when the cost of starvation exceeds that of the risk of predation (see review by Ferrari et al. 2009), which can vary across predator species, although we cannot directly assess this here. It is also possible that prey intimidation by a given predator and the efficiency of prey capture by that predator may not be correlated in the field, especially if the predator types that capture the most prey are cryptic and able to evade detection by their prey (Brown et al. 1999). As the risk posed by a predator is, in effect, a property of the prey and its ability to perceive the potential threat (Brown et al. 1999), predator efficiency and the degree of prey antipredator behavior may not always be expected to directly correlate in the field.

\section{Predator richness and NCES}

Because the presence of multiple predator species can nonadditively influence prey behavior (e.g., Crowder et al. 1997), it is possible that increasing predator richness 

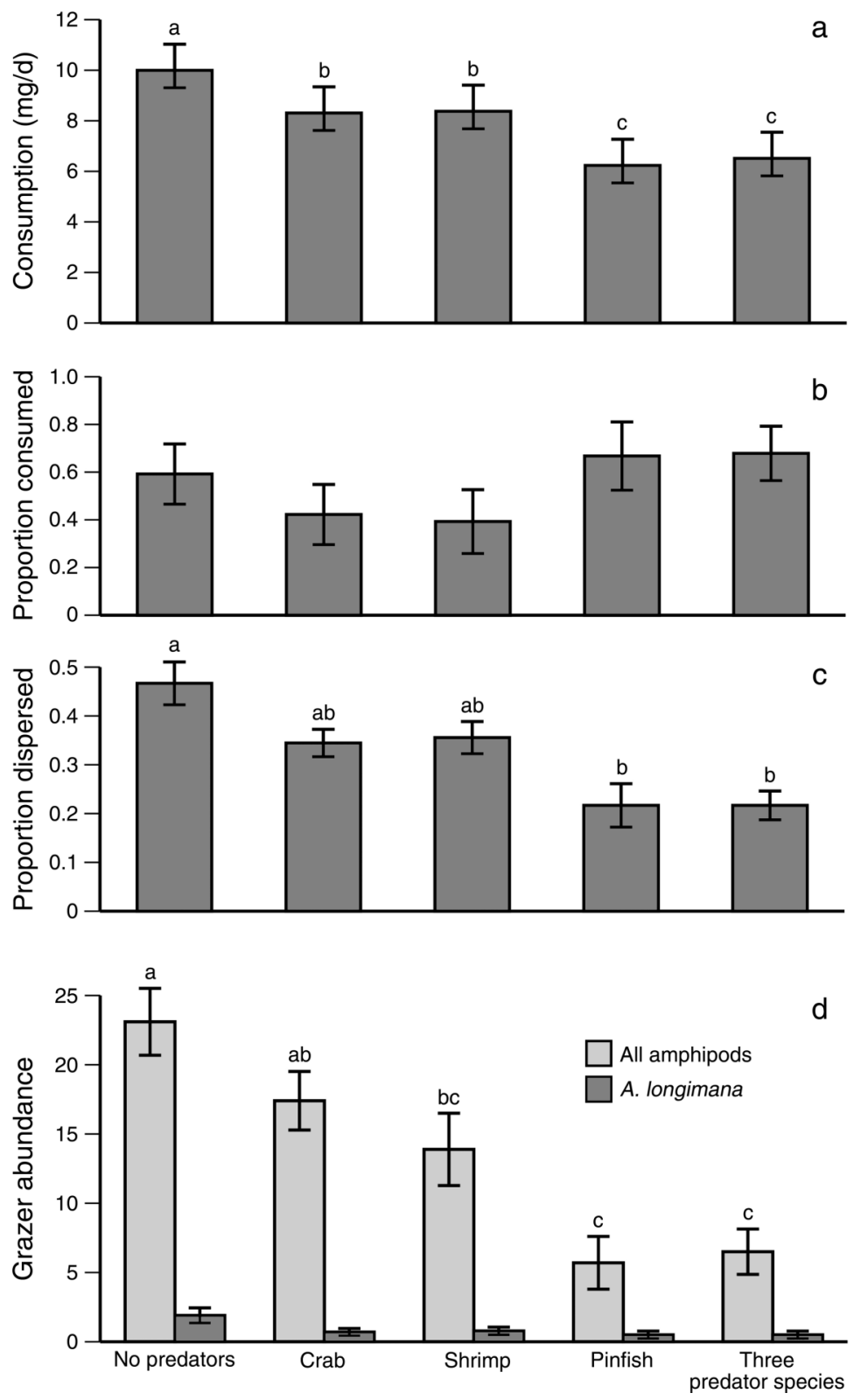

FIG. 7. Effects of predator cues on grazer (Ampithoe longimana) behavior: (a) grazing rate (model based estimates of consumption per amphipod per day), (b) proportion of the alga Dictyota menstrualis consumed compared to a control diet, (c) dispersal in mesocosms, and (d) colonization of algae in the field. Values are means \pm SE [model-based estimates are used in panels (a) and (b)]. Different lowercase letters indicate significant differences $(P<0.05)$ from comparisons based on Bonferroni corrections.

could alter NCEs, either decreasing or increasing them, and subsequently, the strength of the trophic cascade. We documented increased antipredator behavior (reduced grazing, dispersal, and colonization) and reduced prey production with exposure to cues from multiple predators relative to responses to predator monocultures (Table 2). Other studies have reported similar findings. For example, Steffan and Snyder (2010) observed reduced caterpillar feeding and promotion of plant biomass in more predator rich communities, likely due to elevated encounters with their predators in these assemblages. Byrnes et al. (2006) also found that although increasing predator richness did not affect herbivore density, it did promote total kelp biomass by reducing overall grazing by the herbivore community.

Although our measured effects of the predator polycultures on their prey populations could be due more to the presence of pinfish (albeit at one-third their density compared to the pinfish monocultures) than to the number of species (i.e., a sampling effect rather than 
a richness effect), the calculated $D_{\mathrm{T}}$ and $D_{\mathrm{MAX}}$ values (Table 2) suggest otherwise. However, if NCEs caused by pinfish (and other predators) in this system are not density dependent, and one individual had the same NCEs on prey populations as three, then polyculture effects could indeed be due largely or entirely to the presence of pinfish, rather than a nonadditive richness effect. Our results (see Appendix F) suggest that antipredator behaviors of A. longimana are predator density dependent at the densities tested here (one vs. three pinfish), although this density effect did not persist with subsequent increases in predator density (e.g., three vs. six pinfish) indicating potential cue saturation and/or a threshold of prey antipredator response.

\section{Conclusions}

Interpreting the results of multipredator experiments can be challenging due to emergent predator effects and feedbacks from indirect trophic interactions (Sih et al. 1998). Here we examined how the presence of multiple predators affects prey behavior, but it may also alter predator behavior with consequences for predator efficiency (Rahel and Stein 1988, Soluk and Collins 1988, Crowder et al. 1997, Steffan and Snyder 2010). In addition, although predators may affect specific prey antipredator behaviors such as dispersal, this may decrease or increase prey vulnerability in the field where predators interact both nonconsumptively and consumptively with their prey. Comprehensive examinations of both consumptive and nonconsumptive predator-prey interactions under realistic conditions with multiple predator species are necessary for effective predictions of the effects of predators on ecosystem functioning.

Understanding the role of NCEs is recognized as integral to predicting the net effects of predators on the structure and functioning of ecological communities (Stachowicz et al. 2007, Peckarsky et al. 2008). Given the persistence of behavioral interactions over time and the fact that that trophic cascades are common features of marine systems (Shurin et al. 2002), changes in predator communities may have widespread effects on prey behavior with cascading impacts on marine communities. If predator cues have large spatial and temporal persistence, predator exclusion experiments in the field may underestimate the total effect of predators on prey dynamics as NCEs from local, natural predator communities may influence prey dynamics within experimental enclosures. Additionally, interactions among predators may drive prey responses and studies partitioning nonconsumptive and consumptive predator-predator interactions may further clarify mechanisms by which changes in the predator community impact prey populations. While we found that shortterm behavioral responses of prey to cues from their predators generally correlated with reduced prey population growth over time, selection of appropriate behaviors with strong fitness consequences may be challenging. Future work on nonconsumptive and other nonadditive effects across long timescales in a broader food web context featuring multiple, interacting predator and prey species will contribute to our ability to predict the effects of changing predator communities.

\section{ACKNOWLEDGMENTS}

We thank E. Sotka, J. Stachowicz, and C. H. Peterson for intellectual support, J. Weiss and M. Fabrizio for statistical advice, M. Simpson and C. Nicolini for field assistance, and M. O'Connor, J. E. Duffy, and anonymous reviewers for comments on this manuscript. Research was conducted under IACUC protocol ID 07-142.0 at UNC-CH. Funding support came from UNC's Institute of Marine Sciences, NSF grant OCE-0623736 to J. F. Bruno, and a UNC Wilson Award to P. L. Reynolds.

\section{Literature Cited}

Abrams, P. A. 1995. Implications of dynamically variable traits for identifying, classifying, and measuring direct and indirect effects in ecological communities. American Naturalist 146:112-134.

Begon, M., C. R. Townsend, and I. L. Harper. 2006. Ecology: from individuals to ecosystems. Blackwell Publishing, Oxford, UK.

Berger, J. 2010. Fear-mediated food webs. Pages 241-253 in J. Terborgh and J. A. Estes, editors. Trophic cascades: predators, prey and the changing dynamics of nature. Island Press, Washington, D.C., USA.

Berger, K. M., E. M. Gese, and J. Berger. 2008. Indirect effects and traditional trophic cascades: a test involving wolves, coyotes, and pronghorn. Ecology 89:818-828.

Boeing, W. J., B. Wissel, and C. W. Ramcharan. 2010. Can costs and benefits of Daphnia defense against fish be measured in a field experiment? Fundamental and Applied Limnology 176:1-10.

Bolnick, D. I., and E. L. Preisser. 2005. Resource competition modifies the strength of trait-mediated predator-prey interactions: a meta-analysis. Ecology 86:2771-2779.

Bousfield, L. E. 1973. Shallow-water gammaridean amphipoda of New England. Cornell University Press, Ithaca, New York, USA.

Brown, J. S., J. W. Laundre, and M. Gurung. 1999. The ecology of fear: optimal foraging, game theory, and trophic interactions. Journal of Mammalogy 80:385-399.

Bruno, J. F., K. E. Boyer, J. E. Duffy, S. C. Lee, and J. S. Kertesz. 2005. Effects of macroalgal species identity and richness on primary production in benthic marine communities. Ecology Letters 8:1165-1174.

Bruno, J. F., and M. I. O'Connor. 2005. Cascading effects of predator diversity and omnivory in a marine food web. Ecology Letters 8:1048-1056.

Burks, R. L., E. Jeppesen, and D. M. Lodge. 2000. Macrophyte and fish chemicals suppress Daphnia growth and alter lifehistory traits. Oikos 88:139-147.

Byrnes, J., J. J. Stachowicz, K. M. Hultgren, A. R. Hughes, S. V. Olyarnik, and C. S. Thornber. 2006. Predator diversity strengthens trophic cascades in kelp forests by modifying herbivore behaviour. Ecology Letters 9:61-71.

Castro, B., S. Consciência, and F. Gonçalves. 2007. Life history responses of Daphnia longispina to mosquitofish (Gambusia holbrooki) and pumpkinseed (Lepomis gibbosus) kairomones. Hydrobiologia 594:165-174.

Creel, S. 2011. Toward a predictive theory of risk effects: hypotheses for prey attributes and compensatory mortality. Ecology 92(12):2190-2195.

Creel, S., and D. Christianson. 2008. Relationships between direct predation and risk effects. Trends in Ecology and Evolution 23:194-201. 
Crowder, L. B., D. D. Squires, and J. A. Rice. 1997. Nonadditive effects of terrestrial and aquatic predators on juvenile estuarine fish. Ecology 78:1796-1804.

Cruz-Rivera, E., and M. E. Hay. 2001. Macroalgal traits and the feeding and fitness of an herbivorous amphipod: the roles of selectivity, mixing, and compensation. Marine Ecology Progress Series 218:249-266.

Dill, L. M., M. R. Heithaus, and C. J. Walters. 2003. Behaviorally mediated indirect interactions in marine communities and their conservation implications. Ecology 84:1151-1157.

Duffy, J. E., and M. E. Hay. 1991. Food and shelter as determinants of food choice by an herbivorous marine amphipod. Ecology 72:1286-1298.

Duffy, J. E., and M. E. Hay. 2000. Strong impacts of grazing amphipods on the organization of a benthic community. Ecological Monographs 70:237-263.

Edgar, G. J. 1990. The use of the size structure of benthic macrofaunal communities to estimate faunal biomass and secondary production. Journal of Experimental Marine Biology and Ecology 137:195-214.

Ferrari, M. C. O., A. Sih, and D. P. Chivers. 2009. The paradox of risk allocation: a review and prospectus. Animal Behaviour 78:579-585.

Giguère, L. A., and T. G. Northcote. 1987. Ingested prey increase risks of visual predation in transparent Chaoborus larvae. Oecologia 73:48-52.

Hanazato, T., K. Fueki, and M. Yoshimoto. 2001. Fishinduced life-history shifts in the cladocerans Daphnia and Simocephalus: are they positive or negative responses? Journal of Plankton Research 23:945-951.

Hawlena, D., and O. J. Schmitz. 2010. Physiological stress as a fundamental mechanism linking predation to ecosystem functioning. American Naturalist 176:537-556.

Hay, M. E., and J. P. Sutherland. 1988. The ecology of rubble structures of the South Atlantic Bight: a community profile. National Wetlands Research Center, Washington, D.C., USA.

Heithaus, M. R., A. Frid, A. J. Wirsing, and B. Worm. 2008. Predicting ecological consequences of marine top predator declines. Trends in Ecology and Evolution 23:202-210.

Johansson, F., and J. Andersson. 2009. Scared fish get lazy, and lazy fish get fat. Journal of Animal Ecology 78:772-777.

Kraus, J. M., and J. R. Vonesh. 2010. Feedbacks between community assembly and habitat selection shape variation in local colonization. Journal of Animal Ecology 79:795802.

Layman, C. A., J. E. Allgeier, A. D. Rosemond, C. P. Dahlgren, and L. A. Yeager. 2011. Marine fisheries declines viewed upside down: human impacts on consumer-driven nutrient recycling. Ecological Applications 21:343-349.

Lima, S. L. 2009. Predators and the breeding bird: behavioral and reproductive flexibility under the risk of predation. Biological Reviews 84:485-513.

Lima, S. L., and P. A. Bednekoff. 1999. Temporal variation in danger drives antipredator behavior: the predation risk allocation hypothesis. American Naturalist 153:649-659.

Lima, S. L., and L. M. Dill. 1990. Behavioral decisions made under the risk of predation: a review and prospectus. Canadian Journal of Zoology 68:619-640.

Lönnstedt, O. M., and M. I. McCormick. 2011. Growth history and intrinsic factors influence risk assessment at a critical life transition for a fish. Coral Reefs 30:805-812.

Loreau, M. 1998. Separating sampling and other effects in biodiversity experiments. Oikos 82:600-602.

Mark1, H., and J. Tautz. 1975. The sensitivity of hair receptors in caterpillars Barathra brassicae L. (Lepidoptera, Noctuidae) to particle movement in a sound field. Journal of Comparative Physiology 99:79-87.

Martin, C. W., F. J. Fodrie, and K. L. Heck. and J. Mattila 2010. Differential habitat use and antipredator response of juvenile roach (Rutilus rutilus) to olfactory and visual cues from multiple predators. Oecologia 162:893-902.

McIntosh, A. R., and B. L. Peckarsky. 1999. Criteria determining behavioural responses to multiple predators by a stream mayfly. Oikos 85:554-564.

Molis, M., I. Preuss, A. Firmenich, and J. Ellrich. 2011. Predation risk indirectly enhances survival of seaweed recruits but not intraspecific competition in an intermediate herbivore species. Journal of Ecology 99:807-817.

Nelson, E. H., C. E. Matthews, and J. A. Rosenheim. 2004. Predators reduce prey population growth by inducing changes in prey behavior. Ecology 85:1853-1858.

Nelson, W. G. 1978. The community ecology of seagrass amphipods: predation and community structure, life histories, and biogeography. Duke University, Durham, North Carolina, USA.

Nelson, W. G. 1979a. An analysis of structural pattern in an eelgrass (Zostera marina L.) amphipod community. Journal of Experimental Marine Biology and Ecology 39:231-264.

Nelson, W. G. 1979b. Experimental studies of selective predation on amphipods: Consequences for amphipod distribution and abundance. Journal of Experimental Marine Biology and Ecology 38:225-245.

O'Connor, M. I. 2009. Warming strengthens an herbivoreplant interaction: linking individual responses to temperature with changes in community structure. Ecology 90:388-398.

O'Connor, M. I., and J. F. Bruno. 2009. Predator richness has no effect in a diverse marine food web. Journal of Animal Ecology 78:732-740.

Orrock, J. L., L. L. Dill, A. Sih, J. Grabowski, S. Peacor, B. Peckarsky, E. Preisser, and E. Werner. 2010. Predator effects in predator-free space: the remote effects of predators on prey. Open Ecology Journal 3:22-30.

Orrock, J. L., J. H. Grabowski, J. H. Pantel, S. D. Peacor, B. L. Peckarsky, A. Sih, and E. E. Werner. 2008. Consumptive and nonconsumptive effects of predators on metacommunities of competing prey. Ecology 89:2426-2435.

Orth, R., K. Heck, and J. van Montfrans. 1984. Faunal communities in seagrass beds: a review of the influence of plant structure and prey characteristics on predator-prey relationships. Estuaries and Coasts 7:339-350.

Pangle, K. L., S. D. Peacor, and O. E. Johannsson. 2007. Large nonlethal effects of an invasive invertebrate predator on zooplankton population growth rate. Ecology 88:402-412.

Peacor, S. D. 2002. Positive effect of predators on prey growth rate through induced modifications of prey behaviour. Ecology Letters 5:77-85.

Peckarsky, B. L., P. A. Abrams, D. I. Bolnick, L. M. Dill, J. H. Grabowski, B. Luttbeg, J. L. Orrock, S. D. Peacor, E. L. Preisser, O. J. Schmitz, and G. C. Trussell. 2008. Revisiting the classics: considering nonconsumptive effects in textbook examples of predator-prey interactions. Ecology 89:24162425.

Peckarsky, B. L., and A. R. McIntosh. 1998. Fitness and community consequences of avoiding multiple predators. Oecologia 113:565-576.

Persson, A. 1997. Effects of fish predation and excretion on the configuration of aquatic food webs. Oikos 79:137-146.

Preisser, E. L., D. I. Bolnick, and M. E. Benard. 2005. Scared to death? The effects of intimidation and consumption in predator-prey interactions. Ecology 86:501-509.

Preisser, E. L., J. L. Orrock, and O. J. Schmitz. 2007. Predator hunting mode and habitat domain alter nonconsumptive effects in predator-prey interactions. Ecology 88:2744-2751.

R Design Core Team. 2011. R version 2.14.0. R Project for Statistical Computing, Vienna, Austria. www.r-project.org

Rahel, F. J., and R. A. Stein. 1988. Complex predator-prey interactions and predator intimidation among crayfish, piscivorous fish, and small benthic fish. Oecologia 75:94-98. Raimondi, P. T., S. E. Forde, L. F. Delph, and C. M. Lively. 2000. Processes structuring communities: evidence for trait- 
mediated indirect effects through induced polymorphisms Oikos 91:353-361.

Resetarits, W. J., and C. A. Binckley. 2009. Spatial contagion of predation risk affects colonization dynamics in experimental aquatic landscapes. Ecology 90:869-876.

Reynolds, P. L., and E. E. Sotka. 2011. Non-consumptive predator effects indirectly influence marine plant biomass and palatability. Journal of Ecology 99:1272-1281.

SAS Institute. 2008. SAS version 9.2. SAS Institute, Cary, North Carolina, USA.

Schmitz, O. J. 1998. Direct and indirect effects of predation and predation risk in old-field interaction webs. American Naturalist 151:327-342.

Schmitz, O. J. 2008. Effects of predator hunting mode on grassland ecosystem function. Science 319:952-954.

Schmitz, O. J., D. Hawlena, and G. C. Trussell. 2010. Predator control of ecosystem nutrient dynamics. Ecology Letters 13:1199-1209.

Schneider, C. W., R. B. Searles, and J. S. Child. 1991. Seaweeds of the southeastern United States: Cape Hatteras to Cape Canaveral. Duke University Press, Durham, North Carolina, USA.

Shurin, J. B., E. T. Borer, E. W. Seabloom, K. Anderson, C. A. Blanchette, B. R. Broitman, S. D. Cooper, and B. Halpern. 2002. A cross-ecosystem comparison of the strength of trophic cascades. Ecology Letters 5:785-791.

Sih, A. 1994. Predation risk and the evolutionary ecology of reproductive behavior. Journal of Fish Biology 45:111-130.

Sih, A., G. Englund, and D. Wooster. 1998. Emergent impacts of multiple predators on prey. Trends in Ecology and Evolution 13:350-355.

Smee, D., and M. Weissburg. 2006. Hard clams (Mercenaria mercenaria) evaluate predation risk using chemical signals from predators and injured conspecifics. Journal of Chemical Ecology 32:605-619.

Soluk, D. A., and N. C. Collins. 1988. A mechanism for interference between stream predators: responses of the stonefly Agnetina capitata to the presence of sculpins. Oecologia 76:630-632.

Sotka, E. E., and M. E. Hay. 2002. Geographic variation among herbivore populations in tolerance for a chemically rich seaweed. Ecology 83:2721-2735.

Sotka, E. E., and P. L. Reynolds. 2011. Rapid experimental shifts in host use traits of a polyphagous marine herbivore reveals fitness costs on alternative hosts. Evolutionary Ecology 25:1335-1355.

Stachowicz, J. J., J. F. Bruno, and J. E. Duffy. 2007. Understanding the effects of marine biodiversity on communities and ecosystems. Annual Review of Ecology, Evolution, and Systematics 38:739-766.

Steffan, S. A., and W. E. Snyder. 2010. Cascading diversity effects transmitted exclusively by behavioral interactions. Ecology 91:2242-2252.

Stibor, H., and D. M. Navarra. 2000. Constraints on the plasticity of Daphnia magna influenced by fish-kairomones. Functional Ecology 14:455-459.

Stoner, A. W. 1982. The influence of benthic macrophytes on the foraging behavior of pinfish, Lagodon rhomboides. Journal of Experimental Marine Biology and Ecology 58:271-284.

Travers, M., M. Clinchy, L. Zanette, R. Boonstra, and T. D. Williams. 2010. Indirect predator effects on clutch size and the cost of egg production. Ecology Letters 13:980-988.

Trussell, G. C., P. J. Ewanchuk, and M. D. Bertness. 2003. Trait-mediated effects in rocky intertidal food chains: predator risk cues alter prey feeding rates. Ecology 84:629640

Trussell, G. C., C. M. Matassa, and B. Luttbeg. 2011. The effects of variable predation risk on foraging and growth: less risk is not necessarily better. Ecology 92:1799-1806.

Turner, A. M. 2008. Predator diet and prey behaviour: freshwater snails discriminate among closely related prey in a predator's diet. Animal Behaviour 76:1211-1217.

Underwood, A. J. 1997. Experiments in ecology: their logistical design and interpretation using analysis of variance. Cambridge University Press, Cambridge, UK.

van der Merwe, M., and J. S. Brown. 2008. Mapping the landscape of fear of the cape ground squirrel (Xerus inauris). Journal of Mammalogy 89:1162-1169.

Venzon, M., A. Janssen, A. Pallini, and M. W. Sabelis. 2000. Diet of a polyphagous arthropod predator affects refuge seeking of its thrips prey. Animal Behaviour 60:369-375.

Werner, E. E., and S. D. Peacor. 2003. A review of traitmediated indirect interactions in ecological communities. Ecology 84:1083-1100.

Wooster, D. E. 1998. Amphipod (Gammarus minus) responses to predators and predator impact on amphipod density. Oecologia 115:253-259.

\section{Supplemental Material}

\section{Appendix A}

Predator efficiency of prey capture (Ecological Archives M083-005-A1).

\section{Appendix B}

Experimental images (Ecological Archives M083-005-A2).

Appendix C

Methods for chlorophyll $a$ analysis (Ecological Archives M083-005-A3)

\section{Appendix D}

Macroalgal composition (Ecological Archives M083-005-A4).

Appendix E

Predator treatment effects on grazer size distributions (Ecological Archives M083-005-A5).

Appendix F

Effects of pinfish density on grazer feeding (Ecological Archives M083-005-A6).

\section{Data Availability}

Data associated with this paper have been deposited in Dryad: http://dx.doi.org/10.5061/dryad.kq3c6 